\title{
Práticas Escolares de Matemática no Instituto Nossa Senhora da Piedade em Ilhéus: desafios para a educadora baiana Martha Dantas
}

\author{
Mathematics School Practices at the Nossa Senhora da Piedade Institute in \\ Ilheus: challenges for the brasilian educator Martha Dantas
}

\author{
Larissa Pinca Sarro Gomes* \\ Maria Ângela Miorim **
}

\begin{abstract}
Resumo
Neste artigo apresentamos alguns aspectos das práticas escolares de Matemática do Instituto Nossa Senhora da Piedade, localizado em Ilhéus, Bahia, no período em que os professores desta instituição de ensino utilizaram a coleção didática intitulada Matemática, entre 1989 e 1998. A experiência dos professores com esta coleção teve início no final de 1989, com o curso de formação ministrado por Martha Dantas, uma das autoras da coleção. Considerando a metodologia da História Oral, produzimos documentos escritos a partir da realização de entrevistas com os professores e com Eliana Costa Nogueira, outra autora da coleção. Compreendendo, com Michel de Certeau, as práticas ou as maneiras de fazer como operações dos usuários aos produtos culturais que lhes são oferecidos ou impostos, interpretamos como os conteúdos matemáticos e as orientações pedagógicas, sugeridos pelos autores da coleção, são postos à leitura dos professores e por eles ressignificados ao considerarem suas experiências e as necessidades que surgiram ao trabalhar essa coleção com seus alunos.
\end{abstract}

Palavras-chave: Práticas Escolares. Cultura Escolar. História Oral. História da Educação Matemática.

\begin{abstract}
This article presents some aspects of math school practices in Nossa Senhora da Piedade Institute, located in Ilhéus, Bahia, in a period when the teachers of this educational institution used the didactic series entitled Mathematics, between 1989 and 1998. The teachers' experience with this series begins in late 1989, with the training course taught by Martha Dantas, one of the authors of the series. Considering the Oral History methodological approach, we produced written documents from interviews with teachers and Eliana Costa Nogueira, another author of the books. After understanding, with Michel de Certeau, the practices or ways of doing operations of users to cultural products offered or imposed to them, we interpreted as mathematical content and pedagogical guidelines suggested by the authors of the collection, are read by teachers and reinterpreted to consider their experiences and needs that arise when working with this series with their students.
\end{abstract}

Keywords: School Practices. School Culture. Oral History. History of Mathematics Education.

\footnotetext{
* Doutora em Educação pela Faculdade de Educação da Universidade Estadual de Campinas (UNICAMP), Campinas/SP. Docente do Programa de Pós-Graduação em Educação Matemática da Universidade Estadual de Santa Cruz (UESC), Ilhéus/BA. Endereço para correspondência: Campus Soane Nazaré de Andrade, Rod. Jorge Amado, Km 16, Bairro Salobrinho, Ilhéus/BA, CEP 45662- 900. E-mail: lpsgomes@uesc.br.

** Doutora em Educação pela Faculdade de Educação da Universidade Estadual de Campinas (UNICAMP), Campinas/SP. Docente do Departamento de Ensino e Práticas Culturais da Faculdade de Educação da Universidade Estadual de Campinas (FE-UNICAMP), Campinas/SP. Endereço para correspondência: Av. Bertrand Russell, 80, Cidade Universitária "Zeferino Vaz", Campinas-SP, CEP 13083-865. E-mail: miorim@unicamp.br.
} 


\section{Introdução}

Aspectos da trajetória profissional da educadora matemática baiana Martha Dantas, bem como suas contribuições para mudanças na Matemática escolar brasileira e na formação inicial e continuada de professores desta área, particularmente nas décadas de 1960 e 1970, período áureo do Movimento da Matemática Moderna, já foram objeto de diversos estudos históricos brasileiros. Neste artigo, no entanto, centramos nossa atenção em uma experiência específica dessa educadora baiana com professores de Matemática do Instituto Nossa Senhora da Piedade (INSP), localizado na cidade de Ilhéus, realizada entre 1989 e 1998, período em que novas propostas para a Matemática escolar estavam sendo implantadas no Brasil.

O Instituto Nossa Senhora da Piedade, mantido pelas irmãs Ursulinas, é uma escola com quase cem anos de existência ${ }^{1}$. Durante esse longo período de funcionamento, seus professores acompanharam as novas orientações para o ensino de matemática por meio da participação em cursos, como os oferecidos pela CADES - Campanha de Aperfeiçoamento e Difusão do Ensino Secundário, e por meio da adoção de coleções didáticas com propostas mais recentes, escritas por autores reconhecidos nacionalmente e publicadas por grandes editoras.

No último ano da década de 1980, no entanto, os professores se preparavam para realizar uma experiência diferente, que tinha como centro um curso para conhecer a proposta de uma coleção de livros didáticos de Matemática, a ser implantada a partir do ano seguinte na escola. Ao contrário do que ocorria em outros anos, quando os professores decidiam sobre os livros que seriam utilizados em sala de aula, a sugestão de realização do curso, bem como do uso da coleção, partiu da irmã Georgina Costa, então diretora do colégio ilheense. A decisão da diretora teria sido motivada pelo conhecimento de uma experiência bem sucedida com o uso da coleção no Colégio Nossa Senhora da Soledade de Salvador, da mesma Congregação, iniciado um ano antes.

A coleção que seria o objeto central do curso tinha um título tradicional: Matemática. Ela não era publicada nem distribuída por uma reconhecida editora nacional, como outras coleções já utilizadas pela escola. Os autores não eram recordistas de venda de livros didáticos de Matemática no Brasil naquele período, mas faziam parte de um grupo de professores baianos, que havia tido destaque nas discussões e propostas do Movimento da

1 O INSP iniciou suas atividades em 1916. 
Matemática Moderna no Brasil. Eram eles: Martha Maria de Sousa Dantas, Eliana Costa Nogueira, Neide Clotilde de Pinho e Souza, Eunice Conceição Guimarães e Omar Catunda.

Outras versões da coleção Matemática já haviam sido implantadas em diferentes cursos e escolas públicas baianas na década anterior. No entanto, as escolas das Ursulinas foram as primeiras e, provavelmente, as únicas, da rede particular da Bahia que utilizaram a coleção $^{2}$. Os laços afetivos estabelecidos por Martha com a Congregação, há mais de cinquenta anos, quando ela era aluna interna do Colégio Nossa Senhora da Soledade e cursava o magistério, podem ter influenciado a escolha da coleção, ainda que tardia.

Ao final do ano de 1989, os professores de Matemática do Instituto Nossa Senhora da Piedade (INSP) se preparavam para participar de um curso de formação ministrado pela antiga aluna da Congregação, Martha. O curso era a primeira etapa da experiência, que teria outros encontros durante o período de utilização da coleção Matemática na escola. Nestes encontros, seriam desencadeadas ações que introduziriam novas práticas de ensino de Matemática, nem sempre prescritas pela coleção Matemática.

Neste artigo, centraremos nossa atenção nas práticas escolares relacionadas à utilização da coleção Matemática no Instituto Nossa Senhora da Piedade, no período de 1990 a 1998. Para isso, consideramos, com Michel de Certeau, as "práticas ou as maneiras de fazer" como "operações" dos usuários aos produtos culturais que lhes são oferecidos ou impostos (CERTEAU, 2008, p. 39).

\section{A História Oral e a produção de fontes históricas}

Para a escrita deste artigo, além dos quatro volumes da coleção Matemática e de outras publicações de autoria de Martha Dantas, utilizamos diversos documentos, dentre os quais se encontram os textos usados durante o curso de formação. No entanto, privilegiamos documentos constituídos a partir de entrevistas realizadas com professores, que estiveram

\footnotetext{
${ }^{2}$ Em depoimento de 1996, Martha Dantas relatou que a coleção Matemática foi utilizada em várias escolas públicas da capital baiana. A autora mencionou o ano em que a coleção começou a ser utilizada nas escolas públicas, mas não citou por quanto tempo os professores a utilizaram em suas aulas. Em 1975, as fichas da coleção começaram a ser utilizadas no Colégio Estadual Duque de Caxias; no final da década de 1970, foram utilizadas no Centro Educacional Carneiro Ribeiro, conhecido como Escola Parque, sendo interrompida a experiência com a substituição do diretor e novamente retomada a partir do segundo semestre de 1987; em 1990, a coleção começou a ser utilizada na Escola Reitor Miguel Calmon - SESI - FIEB; e, em 1991, a coleção foi utilizada no Instituto Municipal de Educação. Martha Dantas também menciona o uso dos quatro livros da coleção pela professora Arlete Cerqueira Lima durante um curso de formação de professores de escolas públicas da periferia de Feira de Santana. Em nossos estudos, não localizamos registros de que a coleção Matemática tenha sido utilizada em outros Estados (DANTAS, 1996).
} 
presentes no curso e/ou utilizaram a coleção em sala de aula, e com uma das autoras da coleção Matemática.

Considerando a História Oral como uma metodologia de pesquisa adequada para a investigação de nosso interesse, inspiramo-nos em trabalhos realizados pelo GHOEM Grupo de História Oral e Educação Matemática. Com Garnica (2005), entendemos que uma metodologia é sempre construída no movimento da pesquisa e não se resume a apenas um conjunto de procedimentos, mas a um conjunto de procedimentos e pressupostos teóricos que devem ser confrontados e avaliados durante a pesquisa.

Assumindo a História Oral como metodologia de pesquisa, iniciamos o processo para a "criação de fontes a partir da oralidade" (GARNICA, 2011, p. 4). Após identificação e contatos iniciais com possíveis colaboradores, cinco professores e uma coautora da coleção Matemática concordaram em colaborar com nosso estudo. Elaboramos, então, um roteiro para a entrevista com os professores que nos permitisse compreender seus encontros com Martha Dantas no INSP e a forma como utilizaram a coleção Matemática com seus alunos. Com a coautora da coleção elaboramos um roteiro que nos permitisse conhecer suas experiências com o uso da coleção nas escolas da capital baiana e as modificações que os autores foram implementando nos textos da coleção.

Com data, horário e local previamente agendados de acordo com as disponibilidades dos colaboradores, as entrevistas foram realizadas e gravadas em um aparelho portátil de áudio após o esclarecimento do objetivo da investigação que estava sendo realizada e da autorização dos entrevistados para a gravação.

Após a realização das entrevistas, e considerando os apontamentos de Gaertner e Baraldi (2008) e Garnica (2005), nos dedicamos inicialmente às transcrições que, embora se constitua em um processo técnico de passagem do áudio para um texto escrito, exige muita atenção e cuidado. Posteriormente, partindo deste texto, passamos para a etapa da textualização, na qual um novo documento foi produzido a partir da transcrição realizada. Neste processo, buscamos elaborar um novo texto "mais fluente e livre dos vícios da oralidade" (GAERTNER \& BARALDI, 2008, p. 55) e realizamos um "reagrupamento temático", ao fazer um recorte nos depoimentos procurando agrupar os temas que se repetiam (GARNICA, 2005, p. 127). Ao final deste processo, as textualizações foram encaminhadas 
aos entrevistados para conferência e autorização de uso mediante uma carta de cessão de direitos ${ }^{3}$.

\section{O curso de formação de Martha Dantas no Instituto Nossa Senhora da Piedade}

Como estava previsto, os primeiros encontros de Martha Dantas com os professores aconteceram no próprio colégio, no final de 1989. Durante o curso, a educadora baiana ficou hospedada, juntamente com algumas irmãs Ursulinas, em um prédio anexo ao colégio. Ainda nos dias atuais, algumas religiosas que coordenam as atividades administrativas e pedagógicas do INSP residem nesse prédio, construído inicialmente para acomodar alunas internas que permaneciam na Escola durante grande parte do ano e eram monitoradas pelas freiras ${ }^{4}$.

O objetivo do curso de formação para professores de Matemática do INSP, coordenado por Martha Dantas, era discutir a proposta da coleção didática Matemática, que seria implantada, gradativamente, na escola. A previsão era introduzir em 1990 o primeiro volume na $5^{\mathrm{a}}$ série do Primeiro Grau ${ }^{5}$. No ano seguinte, nas $5^{\mathrm{as}}$ e $6^{\mathrm{as}}$ séries, até que, em 1994, todas as séries estivessem utilizando a nova coleção ${ }^{6}$. Seguindo essa previsão, a primeira parte do curso foi destinada ao estudo detalhado das atividades apresentadas no primeiro volume da coleção, bem como à discussão de aspectos centrais da proposta dos autores, que propunha harmonizar a exposição com a descoberta, como rememorou a professora Maria Izabel Nascimento Dias em sua entrevista. Ela se recorda de que, juntamente com os outros professores, teve a oportunidade de estudar a coleção, organizada em fichas de estudos, resolvendo "exercício por exercício, discutindo folha por folha, palavra por palavra, vírgula por vírgula, nos encontros que aconteciam aos sábados em uma sala ventilada do Piedade" (GOMES, 2014, p. 213).

Mais de uma década já se havia passado desde a primeira experimentação da coleção Matemática em escolas da capital baiana. As experiências realizadas durante aquele período possibilitaram à professora de Matemática Martha Dantas identificar dificuldades e

\footnotetext{
${ }^{3}$ Estes documentos encontram-se nos anexos da tese de doutorado intitulada Entre a Exposição e a Descoberta: a coleção Matemática e as práticas escolares relacionadas à sua utilização no Instituto Nossa Senhora da Piedade, defendida pela primeira autora deste artigo, em 2014, na FE-UNICAMP (GOMES, 2014).

${ }^{4}$ Essa prática era comum em escolas de diferentes ordens religiosas. A diretora e as professoras moravam em aposentos construídos próximos à escola ou em um prédio anexo a ela. Isso ocorria, pois as religiosas, ao assumirem a sua vocação, deveriam deixar a família e dedicar-se totalmente aos trabalhos da Congregação. Em algumas Congregações, essa prática persiste até hoje.

${ }^{5}$ Equivalente ao atual $6^{\circ}$ ano do Ensino Fundamental.

${ }^{6}$ A proposta foi implantada conforme o previsto e perdurou até o final de 1998, quando a Instituição optou pela adoção da recém lançada coleção didática Matemática, escrita por Imenes e Lellis e publicada pela Editora Scipione, com primeira edição em 1998.
} 
resistências de professores à adoção da proposta da coleção, que rompia com a prática de aulas expositivas e propunha um trabalho com fichas de estudo, contemplando momentos de trabalho individual e em grupo. O conhecimento dessas dificuldades e resistências certamente contribuiu para mudanças nos textos da coleção, bem como no trabalho com os professores.

As professoras Jurema Lindote e Maria Izabel Dias relembraram a dedicação de Martha Dantas, resolvendo junto com elas as atividades dos livros. Segundo Jurema ${ }^{7}$, quando Martha Dantas "percebia que precisávamos trabalhar melhor algum conteúdo" ela trazia mais atividades e textos "para complementar os estudos" (GOMES, 2014, p. 142). Alguns textos guardados na pasta da professora Jurema eram manuscritos redigidos por Martha, com uma letra legível e bonita. Em um desses textos encontrava-se a resolução de exercícios de geometria propostos no volume Matemática 7 e demonstrações de enunciados do volume Matemática 8. Em outros, eram apresentadas algumas técnicas de adição, subtração e multiplicação que não faziam parte dos textos da coleção Matemática, mas relacionavam-se a questões de revisão das quatro operações básicas da Matemática. Com relação à multiplicação, os escritos exploram diferentes métodos, dentre os quais se encontram o método egípcio ou por duplicação, o método da gelosia e o método em cruz. Outros textos, no entanto, discutiam questões mais amplas, relacionadas a mudanças ocorridas na Matemática escolar.

Os textos da pasta da professora Jurema, bem como as conversas com essa professora e com outros docentes que participaram do curso, nos forneceram indícios do motivo de Martha Dantas ter denominado o seu curso de Curso de Formação. Ela tinha o objetivo não apenas de trabalhar a coleção Matemática com os professores, mas também de discutir aspectos teórico-metodológicos que orientaram a construção dos textos presentes na coleção. Além da leitura de textos de autores que deram suporte à proposta da coleção, Martha também contava aos professores aspectos de sua vida profissional e o contato com autores daqueles textos. Para justificar, por exemplo, a opção pelo trabalho com as transformações geométricas no ensino da geometria e as fichas de estudo, a professora Jurema relembra que "Martha nos contava suas experiências na França, Bélgica e falava muito de Papy e de Felix Klein" (GOMES, 2014, p. 208).

Na época do curso de formação no INSP, Martha Dantas já estava aposentada da universidade e havia participado de vários movimentos de mudanças da Matemática escolar.

\footnotetext{
${ }^{7}$ Esta professora tinha uma pasta com o material utilizado durante o curso de formação e em encontros que aconteceram em outras oportunidades em que Martha esteve no colégio para acompanhar a aplicação da coleção. 
Com tantas experiências, seu curso foi entremeado de histórias de vida, em particular daquelas relacionadas a histórias da Educação Matemática brasileira.

A geometria pelas transformações foi um grande centro do trabalho da coleção, ou como observou o professor Eugênio, era "o fecho de ouro da coleção" (GOMES, 2014, p. 232). Esse tipo de geometria era desconhecido da maioria dos professores que fizeram o curso de formação. Um dos únicos que já haviam tido contato com ela era o professor Eugênio, formado em Engenharia. A professora Jurema relembra que nas atividades de geometria pelas transformações eram utilizados vetores, desenhados em uma malha quadriculada. Na malha eram realizadas diferentes transformações de vetores, tais como homotetias, translações e simetrias. Embora os alunos gostassem das atividades, que envolviam desenhos e cores, eles apresentavam dificuldades para representar o vetor solicitado pela transformação e também para realizar as demonstrações. Essas demonstrações, no entanto, segundo a professora Jurema, "eram mais rápidas" e mais fáceis do que as da Geometria Euclidiana (GOMES, 2014, p. 209).

Após o curso de formação, Martha Dantas continuou a acompanhar o trabalho de implantação da coleção. Em duas reuniões anuais, ela conversava com os professores sobre o andamento da experiência e as dificuldades encontradas por eles e pelos alunos. Nessas oportunidades, ela apresentava aplicações de tópicos estudados, discutia soluções de questões, em especial, diversas soluções apresentadas por alunos nas quais, muitas vezes, os professores não haviam pensado. A possibilidade de diferentes respostas para uma mesma questão era algo que, inicialmente, assustava alguns professores. As discussões realizadas por Martha sobre as respostas diferenciadas possibilitaram aos professores que refletissem sobre a criatividade dos alunos e o papel de alunos e professores na construção do conhecimento. Os alunos deveriam ser incentivados a criar soluções diferenciadas daquela apresentada pelo professor. Como nos disse Eugênio Vargens, os professores não deveriam "podar” os alunos (GOMES, 2014, p. 231).

\section{A coleção Matemática no INSP: uma proposta extemporânea}

A coleção Matemática, a ser adotada no início da década de 1990, apresentava diferenças significativas em relação à coleção utilizada anteriormente no INSP: Matemática e Realidade $^{8}$. Essa coleção, de autoria de Gelson Iezzi, Osvaldo Dolce e Antônio Machado,

\footnotetext{
${ }^{8} \mathrm{O}$ primeiro volume da Coleção Matemática e Realidade que tivemos acesso foi publicada pela Atual Editora Ltda, em 1984.
} 
produzida na década de 1980, aponta em seu título para uma mudança que começava a ocorrer na produção de livros didáticos de Matemática brasileiros, período em que a Matemática Moderna perdia espaço para novas propostas que começavam a circular no cenário nacional. Nessa década, com o fim dos governos militares e os direitos restabelecidos, encontros de professores começaram a ocorrer em vários Estados brasileiros.

Nesses encontros, novos autores eram discutidos e novas propostas para o ensino de Matemática foram construídas. Essa movimentação de propostas e professores gerou a criação dos Encontros Nacionais de Educação Matemática, bem como de uma sociedade específica, em 1989, a Sociedade Brasileira de Educação Matemática, que constituiu um fórum de discussão das questões relacionadas ao ensino e à investigação em Educação Matemática. No mesmo período, vários grupos de estudo e pesquisa foram criados e diferentes propostas foram discutidas e experimentadas.

Embora a primeira edição da coleção Matemática e Realidade ainda mantivesse aspectos da Matemática Moderna, ela já apontava para mudanças que aconteceriam em edições futuras. A coleção Matemática também apresentava ainda vários pontos da Matemática Moderna. Uma diferença entre as duas coleções, no entanto, diz respeito à escrita do aluno no livro. A coleção Matemática e Realidade não tinha espaços para os alunos escreverem - eram livros não consumíveis. Para justificar essa e outras mudanças editoriais, os autores e a editora não apresentam nenhum argumento de natureza pedagógica. A decisão, segundo eles, relacionava-se à situação econômica brasileira e ao custo da obra.

Sensíveis à situação econômica que o país vive, autores e editora decidiram lançar a obra Matemática e Realidade promovendo simplificações de natureza gráfica de forma a obter um barateamento do livro. Em primeiro lugar, foram evitados os espaços em branco que se destinavam às atividades escritas dos alunos em sala de aula, ou seja, produziu-se um livro não consumível. Em segundo lugar, passou-se a um livro impresso em preto e branco (IEZZI et al, 1984).

De fato, na década de 1980, a sociedade brasileira percebia os resultados de mudanças ocorridas no sistema financeiro mundial. O fim da hegemonia dos EUA nos financiamentos aos países dependentes de crédito, como o Brasil, resultou em uma retração do crédito no sistema financeiro internacional de capitais (CHIAPETTI, 2009, p. 73-74). Esse panorama negativo da economia nacional, como mencionado no prefácio, pode ter contribuído para que editores e autores da coleção Matemática e Realidade colocassem no mercado livros mais baratos e que fossem utilizados por mais de um estudante. No entanto, essa decisão também atendia às exigências do Programa Nacional do Livro Didático, que seria lançado no ano seguinte. 
A ampliação do programa de distribuição de obras didáticas do Governo Federal aos alunos matriculados na rede pública de ensino brasileira foi um fator reforçador da edição de livros não consumíveis. Esse programa, que começa a ser ampliado a partir de 1976, momento em que a Fundação Nacional do Material Escolar (Fename) se torna responsável pela execução do programa do livro didático com recursos do Fundo Nacional de Desenvolvimento da Educação (FNDE), criou em 1985, por meio do Decreto $\mathrm{n}^{\circ}$ 91.542, de 19/08/85, o Programa Nacional do Livro Didático (PNLD). O objetivo central do Programa era distribuir livros escolares aos estudantes matriculados nas escolas públicas e que estivessem cursando o $1^{\circ}$ Grau. A orientação era a de que fossem escolhidos, pelos professores, livros reutilizáveis, que seriam aproveitados por vários anos, por diferentes alunos.

Apesar de o volume Matemática e Realidade, ao qual nos referimos anteriormente, ter sido publicado em 1984, ou seja, um ano antes da criação do PNLD que incentivava a edição de livros didáticos reutilizáveis, muito provavelmente os autores e editores, atentos aos movimentos do governo federal de ampliação da distribuição de livros didáticos, bem como de sua proposta de reutilização, adiantaram-se ao cumprimento das novas regras.

A introdução de livros não consumíveis, em um período em que diferentes propostas pedagógicas propunham a escrita no livro de Matemática, exigia que os autores orientassem os alunos para as novas características. Os autores e editores de Matemática e Realidade estavam atentos também a esse aspecto. Em vários momentos, em especial naqueles em que anteriormente era incentivada a escrita nos livros, são colocados alguns alertas aos alunos. Isso ocorre, por exemplo, após a apresentação de listas de exercícios, os autores alertam: "Não escreva no livro. Resolva os exercícios no seu caderno" (IEZZI et al, 1984).

Mesmo nos testes de múltipla escolha, símbolos dos livros didáticos descartáveis, que aparecem ao final de cada capítulo, com o objetivo de revisar o que foi estudado naquele capítulo e que seria facilitado com a colocação apenas de um sinal gráfico no item correto, os autores orientam para que o aluno: "Indique no seu caderno a alternativa correta a cada questão. Não escreva no livro" (IEZZI et al, 1984).

Além da eliminação de espaços para a escrita do aluno nos livros, outro recurso utilizado pela coleção Matemática e Realidade, tendo em vista a redução de custos de produção, foi a eliminação de uso de cores nos livros. Essa decisão, associada a um livro não consumível, certamente, contribuiria para aumentar a chance de a coleção ser adquirida pelo Governo, por meio do PNLD. Competição, mercado, preços muitas vezes decidiam, e ainda decidem, mais que as opções didático-metodológicas. 
Embora o INSP fosse uma escola particular de ensino, nos anos iniciais da década de 1980, a região sofreu muito com a crise econômica do cacau, o que pode ter influenciado a escolha de uma coleção reutilizável. No entanto, outros fatores certamente estiveram envolvidos nessa escolha. Um deles diz respeito à Editora e aos autores. A coleção foi escrita por autores reconhecidos no cenário brasileiro e publicada por uma editora de renome, com grande esquema de divulgação. Além disso, a proposta do PNLD de produzir livros reutilizáveis impôs ao mercado a produção de livros com essas características, diminuindo a oferta de livros descartáveis. Afinal, o maior comprador era, e ainda é, o PNLD. Para concorrer e conseguir aumentar os seus lucros, as editoras investiram em livros que contemplassem as exigências desse Programa. Embora o PNLD fosse, e ainda seja, dirigido às escolas públicas, a rede particular de ensino teve que se adaptar ao novo mercado, utilizando livros não consumíveis ${ }^{9}$ ou, então, produzindo seus próprios textos.

Em 1989, o INSP apostava em uma coleção que era nova neste ambiente escolar: a coleção Matemática. Além de apresentar uma proposta de ensino muito diferenciada da coleção anteriormente utilizada, Matemática e Realidade, a nova coleção que seria adotada tinha uma característica diferente da maior parte das coleções que circulavam no cenário nacional naquele período: ela era consumível. Os autores defendiam o uso de anotações no livro, argumentando que, “À medida que o aluno lê, interpreta e responde, no próprio livro, às questões propostas, verifica-se um considerável ganho de tempo. Este modo de proceder permite, também, eliminar o caderno de notas" (DANTAS, s/d).

Além de economizar tempo e não necessitar de outro caderno, a proposta pedagógica dos autores da coleção, como ocorrera com outras coleções produzidas, em particular, nas décadas de 1970 e 1980, dava suporte a essa decisão. A coleção Matemática foi produzida para que o aluno escrevesse no livro. Por manter tal característica, após as orientações do PNLD, a coleção não tinha mais interesse por parte de editoras e escolas. "A coleção não era interessante porque o aluno escrevia nos livros e isto impedia sua reutilização no ano seguinte", como menciona uma das autoras, Eliana Costa Nogueira, em sua entrevista (GOMES, 2014, p. 225). Defendendo sua proposta de ensino, os autores da coleção Matemática não alteraram as características de seus livros. Sem o apoio de grandes editoras, a coordenadora da coleção, Martha Dantas, "bancava a edição dos livros" (GOMES, 2014, p. 230).

\footnotetext{
${ }^{9}$ Alguns livros didáticos do PNLD são atualmente não reutilizáveis, ou consumíveis. São eles: Alfabetização Matemática, Letramento e Alfabetização, Inglês, Espanhol, Filosofia e Sociologia. Disponível em: http://www.fnde.gov.br/programas/livro-didatico/livro-didatico-apresentacao. Acesso em: 11/03/2015.
} 
Para Martha Dantas, as escritas no corpo do livro tinham funções pedagógicas alinhadas com a proposta metodológica dos autores. $\mathrm{O}$ aluno poderia recorrer ao livro sempre que tivesse uma dúvida e isso o ajudaria a analisar as respostas por ele elaboradas, bem como outras anotações feitas durante as discussões das fichas realizadas em sala de aula. Esses aspectos da metodologia foram enfatizados por Martha Dantas, durante o curso de formação realizado no INSP, como pudemos apreender por depoimentos de professores.

Ao comparar os exercícios apresentados no primeiro volume da coleção Matemática e Realidade com aqueles do primeiro volume da coleção Matemática, referentes a um mesmo conteúdo, percebemos uma grande diferença. No primeiro, cada capítulo estava dividido em unidades e ao final de cada unidade aparecem duas listas de exercícios intitulados: exercícios e exercícios de reforço. Eles referem-se ao mesmo conteúdo abordado na unidade. Várias questões enumeradas são compostas por diversos itens, variando de quatro a oito itens, para a mesma questão. Ao final do capítulo, os autores propõem uma seção intitulada exercícios série final. No capítulo no qual os autores tratam dos números naturais - sistema de numeração decimal, sistema de numeração romano, propriedades da adição, multiplicação e potenciação -, encontramos uma lista com cinquenta e cinco questões, algumas delas, com vários itens. Para realmente finalizar, uma lista com questões de múltipla escolha, que avaliamos serem as tais "questões voltadas para o vestibular", as quais os pais dos alunos não encontraram na coleção Matemática (GOMES, 2014, p. 230).

Não há dúvida de que as concepções dos autores das duas coleções, a respeito do processo de ensino e aprendizagem da Matemática, eram muito distintas. Martha acreditava que o aluno aprende a partir de suas descobertas e não pela memorização ou pela repetição exaustiva de exercícios. No entanto, essas concepções de Martha não eram compartilhadas por todos os professores do INSP, pois, conforme apontamos anteriormente, essas concepções são o resultado de pressupostos teóricos com que o professor teve contato e nos quais acredita, bem como de suas reflexões a partir das experiências vivenciadas em sala de aula.

Ao analisar os dois primeiros volumes da coleção Matemática verificamos que os autores também propõem exercícios de cálculos com enunciados onde se destacam palavras como efetue, resolva as expressões, calcule e complete as lacunas. No entanto, esses exercícios aparecem frequentemente, após os alunos serem interrogados a respeito dos novos conteúdos abordados em cada ficha de estudo. Em algumas fichas, como ressaltou Martha Dantas, os autores fizeram uso da exposição. No entanto, em nenhum dos volumes analisados encontramos a quantidade de exercícios que foram sugeridas pelos autores da coleção Matemática e Realidade. 
A quantidade excessiva de exercícios, apresentando frequentemente instruções como calcule conforme o modelo, observado na coleção Matemática e Realidade, está associada à tendência pedagógica conhecida como tecnicismo pedagógico. De acordo com Dario Fiorentini, essa tendência tecnicista, com origem norte-americana, esteve muito presente nas escolas brasileiras durante as décadas de 1960 e 1970, mas, conforme constatamos, na década de 1980, a proposta dos autores da coleção Matemática e Realidade se aproximavam dessa tendência (FIORENTINI, 1995).

O tecnicismo não fazia parte das concepções de ensino e aprendizagem de Matemática que eram defendidas por Martha Dantas, desde a década de 1950, nos fóruns científicos dos quais participava e em suas publicações. Como professora de Didática da Matemática, Martha conhecia muito bem outras tendências pedagógicas e não era sua intenção associar a proposta da coleção Matemática à tendência tecnicista.

Ainda com relação às atividades ou exercícios propostos na coleção Matemática, outra questão apontada pela professora Maria Izabel está relacionada à falta de "questões com informações da atualidade” (GOMES, 2014, p. 214). Esta crítica, certamente, foi também considerada por Martha Dantas. O professor Eugênio Vargens, em seu depoimento, comenta que, durante o período em que a coleção foi adotada no INSP, Martha Dantas esteve no colégio por diversas vezes e comentou que estava trabalhando na elaboração de aplicações para a parte de geometria, solicitando a contribuição dos professores nessa tarefa, com sugestões de questões que considerassem relevantes.

A proposta dos autores da coleção Matemática estava sintetizada no título da coleção: Matemática - processo entre a exposição e a descoberta. O trabalho com fichas de estudo propunha uma nova abordagem para os conteúdos matemáticos, buscando romper com as aulas exclusivamente expositivas, substituindo-as pelo estudo individual ou em grupo, embora fizesse também uso, quando necessário, da exposição.

$\mathrm{Na}$ apresentação dos livros, os autores destacam que "cada Ficha constitui uma unidade de trabalho na qual, em geral, se pretende que um conceito seja definido, uma regra seja estabelecida ou uma propriedade seja induzida" (DANTAS, s/d). Para o professor Mikhael, os autores apresentam um novo conteúdo de maneira diferente "deixando de apresentar primeiro a definição seguida de exercícios” (GOMES, 2014, p. 217).

A professora Maria Izabel relembrou que durante o curso com Martha, ela ressaltava a importância de ensinar o aluno a estudar sozinho. Seguindo as orientações de Martha, a professora Maria Izabel explicou que, em suas aulas, primeiro fazia a leitura das fichas com os alunos e eles tentavam resolver as questões. Aqueles que não encontravam dificuldades 
prosseguiam com a leitura e resolução das próximas fichas de estudo. Para aqueles com dificuldades, a professora procurava auxiliá-los e, na sequência, discutia com os alunos no quadro suas respostas.

Essas manifestações dos professores seguem as orientações defendidas pelos autores da coleção Matemática, em particular, por Martha Dantas, que explicitou no livro de sua autoria, publicado dois anos antes do curso de formação de professores no INSP, a forma como deveria ser conduzido o trabalho com os alunos:

\begin{abstract}
Os textos são entregues aos alunos e estes passam a trabalhar individualmente ou em grupo. Cada aluno ou cada grupo trabalha no ritmo que lhe convém. O mestre deve intervir o mínimo, a pedido dos alunos ou para forçá-los a refletir. O mestre pode, eventualmente, fazer perguntas evitando, o mais possível, influenciar, diretamente, no trabalho do aluno. Quando os alunos declaram que terminaram suas tarefas, o mestre passa a discutir os resultados dos trabalhos realizados, a fim de chegar a conclusões gerais (DANTAS, 1987, p. 15).
\end{abstract}

\title{
5 A coleção Matemática e práticas escolares no INSP
}

A coleção Matemática atribuía ao professor o papel de orientador e incentivador das atividades sugeridas. Como ocorre com toda proposta pedagógica que incentiva a participação constante do aluno na construção do conhecimento, com a introdução da nova coleção, as aulas no INSP mudaram e se tornaram mais barulhentas. Os alunos discutiam entre si, chamavam o professor, defendiam as suas posições. Essa efervescência de ideias gerava uma situação muitas vezes confundida com bagunça, descontrole. Não era fácil ao professor garantir o silêncio, como muitos estavam acostumados. Esse aspecto foi destacado pela professora Jurema, quando era monitora em uma sala de aula e os alunos utilizavam o primeiro volume da coleção. O professor que ela acompanhava, Luís Eduardo, participou do curso de Martha e foi o primeiro a utilizar a coleção no INSP, na então quinta série. Em suas lembranças, Jurema destaca que:

Os alunos faziam um certo tumulto nas aulas e foi difícil para ele (o professor Luís) acostumar-se com a nova metodologia. Ele não fazia a exposição, mas o método é da exposição à descoberta. Por isso, os alunos faziam muito barulho, cada um perguntando suas dúvidas a respeito de fichas diferentes (GOMES, 2014, p. 211).

Essa maneira diferente de conduzir as aulas exige uma atenção maior do professor com relação às dificuldades individuais e na validação das diferentes respostas apresentadas pelos alunos. Para que isso ocorresse, a professora Jurema ressaltou a importância de organizar a sala e orientar os alunos para os estudos das fichas que seriam "trabalhadas durante a aula". A professora comentou ainda a necessidade de realização de um 
planejamento prévio das atividades que serão discutidas na aula, o que auxiliaria a "manter os alunos trabalhando de maneira organizada" (GOMES, 2014, p. 151).

O professor Eugênio Vargens relembra que no início "não foi fácil a implantação da coleção". Uma dificuldade mencionada por Eugênio diz respeito às diferentes soluções apresentadas pelos alunos, que eram diferentes daquela que ele havia pensado. Isso causava certa insegurança, uma vez que o aluno criava "o seu próprio caminho" e o professor tinha que decidir rapidamente "se aquele caminho que ele encontrou para resolver um problema estava correto" (GOMES, 2014, p. 230-231). Essa não era uma prática comum na experiência do professor, como ainda não é para muitos professores.

No ensino brasileiro de Matemática, existiu, e ainda persiste em algumas escolas, a crença de que apenas uma forma é correta na resolução de um determinado exercício. Nesse tipo de ensino, os alunos não são incentivados a buscar outras soluções. Muitos alunos, até mesmo em cursos superiores, ainda decoram as respostas apresentadas pelos professores. $\mathrm{O}$ livro do professor, que apresenta respostas dos exercícios propostos, muitas vezes reforça essa postura de professores e alunos, ao não discutirem diferentes caminhos para a resolução de um mesmo exercício. Quando algum aluno chega a apresentar uma resolução diferente, o que em algumas escolas é uma situação atípica, o professor reage de formas variadas. Alguns levam a resolução para analisar, outros não dão muita atenção e enfatizam apenas a resolução por ele apresentada ou aquela exposta no livro didático.

Assim como foi apontado pelos professores do INSP, a autora por nós entrevistada também reconheceu que a proposta apresentada na coleção Matemática dava mais trabalho ao professor porque os alunos apresentavam resoluções percorrendo diferentes caminhos e essa pluralidade de respostas deixavam os professores inseguros, como já mencionado. Eliana Nogueira nos contou sua experiência como professora no Colégio Duque de Caxias, e ressaltou que o professor de Matemática:

[...] tinha que estar preparado para a aula porque ele precisava avaliar as respostas dos alunos. Você passava em um grupinho e eles tinham uma dúvida. Em outro grupo já era uma dúvida diferente. E assim, a gente ia sentindo o que o aluno precisava (GOMES, 2014, p. 226).

Nesta ocasião, a professora e autora da coleção Matemática lembrou-se de que colocava no quadro mais de uma resolução para o mesmo problema e depois perguntava aos alunos: Qual é a melhor? O que vocês preferem?

Entretanto, também ressaltou que nem sempre os professores procediam dessa forma em suas aulas e alguns "impunham uma resposta, uma regra, e queriam que os alunos seguissem aquele raciocínio" (GOMES, 2014, p. 226). Esta atitude do professor não deveria 
ser uma constante, mas até mesmo Martha Dantas concordou que em algumas situações o professor é levado a expor para o cumprimento dos programas que lhe são exigidos (DANTAS, 1987).

Atenta a esse problema vivenciado pelos professores nas escolas, Martha Dantas reconhecia que o processo de ensino pautado na descoberta exigia mais tempo. Durante o curso de formação, os docentes já perceberam algumas diferenças com relação à quantidade de exercícios abordados na nova coleção, mas foi com sua utilização em sala de aula que essas diferenças ficaram ainda mais evidentes. Com o uso das fichas da coleção Matemática, os professores sentiram necessidade de complementar as atividades com mais exercícios, com o propósito de trabalhar melhor alguns conteúdos, da mesma forma como acontecera durante o curso de formação.

O professor Mikhael Raad, em sua avaliação do período em que utilizou a coleção, entre 1994 e 1997, comenta sobre alguns aspectos que considera inovadores na coleção Matemática, destacando a "maneira diferente de apresentar os conteúdos", que rompia com a tradicional exposição do professor. Para Mikhael, a exposição tradicional é aquela em que o professor faz a exposição de definições ou propriedades, normalmente no quadro, e, na sequência, passa exercícios para que os alunos resolvam fazendo uso daquilo que foi exposto pelo professor. Ao romper com esta forma de ensino, Mikhael considera que a proposta da coleção "mexe com o comodismo do professor", uma vez que "ele é colocado à prova com relação ao raciocínio e às diversas formas de pensar sobre a matemática” (GOMES, 2014, p. 214).

Esta mudança na postura do professor com relação às aulas de Matemática foi um dos fatores que contribuíram para que a coleção não fosse bem aceita. Na verdade, como ressaltou o professor Eugênio, a rejeição não foi apenas de professores, mas também de pais e alunos.

Quando Martha chega no Piedade, ela apresenta um trabalho que é um "salto a frente". Ela apresenta algumas atividades lúdicas e uma relação diferente com a matemática. O material apresenta os conceitos de maneira intuitiva, sem apresentar uma regra pronta. Os alunos tinham que descobrir (GOMES, 2014, p. 230).

Mas não eram apenas os alunos que tinham que descobrir. Professores e pais também tinham que descobrir ou redescobrir a Matemática. Estudos históricos do campo da Educação, e em particular da Educação Matemática, nos mostram que a implementação das reformas escolares, de novas propostas ou novos manuais escolares acontecem em meio a práticas já estabelecidas e que fazem sentido para muitos professores. Por isso, as mudanças nem sempre são avaliadas positivamente quando procuram romper com práticas didático-pedagógicas já sedimentadas, conforme apontou Wagner Valente em suas investigações (VALENTE, 2008). 
Isto ficou evidente também no INSP. A coleção que era nova naquele ambiente escolar, embora tivesse sido construída em períodos anteriores, contou com a aprovação de alguns e com a rejeição ou dificuldade de adaptação por parte de outros. Os professores que tiveram maior resistência à coleção avaliaram-na como muito diferente daquilo que eles conheciam e em que acreditavam. Como comenta a professora Maria da Conceição:

As minhas aulas não eram diferentes das aulas dos meus professores; eu não acho que ensinava diferente deles. As aulas eram expositivas, tinha o trabalho em grupo mas se o professor não desse uma boa aula expositiva, o aluno não conseguia descobrir por si só e o professor não era reconhecido como um bom professor (GOMES, 2014, p.221).

Nas falas dos professores percebemos o conflito para encontrarem o equilíbrio entre a exposição do professor e as descobertas dos alunos. Em que momentos o professor deveria fazer a exposição dos conteúdos? Quais eram os momentos da descoberta? Essas questões precisavam ser contornadas pelos professores atendendo às diferentes demandas que surgiam em sala de aula, respeitando o ritmo de cada aluno, conforme haviam sugerido os autores.

Os ritmos diferenciados de aprendizagens se davam não só pelas dificuldades dos alunos com os conteúdos matemáticos, mas, também, com a leitura, interpretação, organização e escrita das suas descobertas. O aluno “tinha que saber Português”, relembrou Eugênio Vargens, como sendo uma das discussões realizadas com Martha Dantas durante as oportunidades em que ela se encontrou com os professores no colégio ilheense. Em consequência disto, o professor aponta para um trabalho diferenciado que começa a ser realizado no INSP e "atinge as outras disciplinas", sendo importante a integração realizada “principalmente” com a disciplina de Português (GOMES, 2014, p. 233).

A importância dessa parceria entre os professores de Matemática com os de Língua Portuguesa também foi ressaltada por uma das autoras da coleção, a professora Eliana Costa Nogueira, quando relembrou de sua atuação na escola e a avaliou como uma experiência importante, inclusive para as modificações que foram sendo realizadas na coleção:

No princípio, nós tivemos dificuldade com o Português nas escolas dos bairros. Eles não liam bem e tínhamos que repetir várias vezes uma frase. A professora de Português foi ajudando a gente. Se você dizia assim: - Um número mais o dobro desse número - então eles sabiam o que era. Mas se falasse: - Um número mais o seu dobro - eles não sabiam dizer.

A gente ia ouvindo o aluno e se ele sentisse dificuldade a gente avaliava se deveria aperfeiçoar o material. Por exemplo: "Se - então" é mais fácil para eles compreenderem do que "isso - se aquilo" (GOMES, 2014, p. 226).

A redução na quantidade de exercícios também foi observada pelos pais dos alunos do colégio ilheense, que fizeram uma crítica muito grande à coleção Matemática. A crítica estava pautada na comparação com a coleção anterior, que tinha sido utilizada pelos irmãos de 
alguns alunos que estavam estudando com a nova coleção. Os pais apontavam para a redução dos exercícios e para a falta de questões voltadas para o vestibular.

Além da quantidade reduzida de exercícios, os pais também reclamavam da precariedade da parte gráfica e da encadernação dos exemplares. Eles reclamavam que as folhas se soltavam com o uso. Nós também percebemos problemas na edição dos livros, ao manusear os exemplares que adquirimos no sebo da cidade de Ilhéus. Os livros foram publicados por pequenas editoras, Fator e Contraste, que não tinham profissionais e maquinários necessários a uma boa confecção de livros. Naquele período, as grandes editoras primavam pela produção de livros didáticos com qualidade editorial, usando tipos de papel adequados, incluindo cores, costurando as lombadas, etc.

Outro aspecto da coleção que foi motivo de críticas, bem como de novas propostas, diz respeito à ausência de questões aplicadas, relacionadas ao cotidiano dos alunos. Admitindo a ausência, Martha Dantas incentivava a construção de projetos complementares que valorizassem este aspecto. Na Escola Reitor Miguel Calmon, de Salvador, por exemplo, os professores elaboraram um projeto intitulado Caminhada Matemática no Pelourinho, coordenado por Vera Lúcia Santana Pereira e assessorado por Martha Dantas, que aconteceu em julho de 1993 (DANTAS, 1996, p. 80).

Neste projeto, Eliana Costa Nogueira relembrou que o título já expressava a proposta da atividade, que convidava professores e alunos para uma caminhada matemática no Pelourinho. Durante a caminhada, o grupo "ia observando a fachada das igrejas, as simetrias, a proporção de casas vermelhas e amarelas e eles respondiam algumas questões". "Os alunos levaram pranchetas e se sentaram para responder as questões" (GOMES, 2014, p. 226).

Esse material foi reconhecido pelo professor Eugênio Vargens, dentre outros que foram organizados para a entrevista que concedeu, com o propósito de ajudá-lo em suas rememorações. O professor relembrou que essas atividades foram apresentadas aos professores do INSP, para motivá-los na elaboração de outras questões.

Segundo o professor, inspirado nessa atividade, e em outas apresentadas por Martha Dantas, ele começou a explorar o espaço escolar, que é bastante amplo e rico para o trabalho com a geometria, proposto no terceiro e quarto volumes da coleção Matemática e baseado no conceito de transformações geométricas, conceito esse que os autores mantêm desde as primeiras apostilas por eles redigidas. Mesmo com todas as ressalvas que se fizeram à introdução do conceito de vetores nas coleções anteriores, a estratégia da equipe liderada por 
Martha e Catunda foi manter a introdução aos vetores no ensino da geometria e, também, a proposta de ensinar a geometria por meio das transformações geométricas.

Apesar de Martha ter sugerido que as fichas relacionadas ao ensino de geometria apresentavam uma abordagem intuitiva, a professora Jurema relembrou que os alunos tinham dificuldade para representar os vetores na malha quadriculada e também para realizar as demonstrações solicitadas. Segundo Jurema,

Os alunos se atrapalhavam com a contagem dos quadradinhos e, por isso, eu também utilizava o par de esquadros para fazer a translação de um vetor e os alunos gostavam mais dessa forma, era mais tranquilo. Também apresentavam dificuldades com a homotetia, mas eles gostavam muito dessa parte porque nós trabalhávamos bastante com desenhos. Também gostavam das atividades de translação e simetria (GOMES, 2014, p. 209).

Para o trabalho com as translações, simetria central, axial e homotetia, a professora Jurema, juntamente com o professor Eugênio, começou a elaborar novos exercícios no papel quadriculado. Algumas atividades realizadas pelos alunos foram encontradas no arquivo pessoal da professora Jurema. Nessas atividades, após os alunos encontrarem as transformadas de figuras, que eram fornecidas pelo professor no papel quadriculado, assim como os vetores considerados na questão, coloriam os resultados obtidos.

Ao observar e reconhecer essas atividades, o professor Eugênio avaliou que o ensino da geometria pelas transformações geométricas era proposto de uma forma muito diferente na coleção. De acordo com o professor, motivado por Martha Dantas, ele e a professora Jurema começaram a elaborar novas atividades para serem realizadas em sala de aula e outras, que pudessem explorar o ambiente escolar. Em algumas dessas atividades, após observarem os mosaicos formados nos azulejos e pisos bastante antigos de algumas salas do INSP, os alunos eram incentivados a criar seus próprios mosaicos, usando as transformações geométricas e vetores, que já tinham sido estudados por eles.

A arquitetura do prédio escolar também foi explorada para discutir a simetria com os alunos. Para esse estudo, o professor utilizou o altar da capela do INSP, que é uma réplica da fachada externa construída em estilo neogótico. Em outra atividade, desenvolvida no pátio da escola com os alunos, o objetivo era calcular a medida entre dois pontos distintos do colégio onde não era possível utilizar apenas uma trena. Eugênio, juntamente com os alunos, utilizaram bússolas e trenas, e foram traçando vetores que os representassem para, finalmente, calcular a distância desejada (GOMES, 2014, p. 232).

Essas práticas dos professores, desenvolvidas no cotidiano do INSP, nos fornecem alguns indícios de como se deu a relação dos professores com a coleção Matemática. As diferentes atividades, criadas pelos professores, surgiram a partir do uso da coleção, das 
necessidades por eles percebidas em sala de aula e de suas experiências como professores. Nesse sentido, conforme ressaltou Michel de Certeau (2008), são maneiras de fazer dos professores, consumidores da coleção. Os conteúdos matemáticos e as orientações pedagógicas, sugeridos pelos autores da coleção, são postos à leitura dos professores do INSP, que o fazem considerando suas experiências nesse ambiente escolar e as necessidades que surgem, ao trabalharem a coleção com os alunos, em sala de aula. Assim, conteúdos e métodos de ensino postos à leitura são ressignificados pela tática de apropriação dos professores.

\section{Algumas palavras finais}

Nos encontros de Martha Dantas com os professores do INSP, foi discutida em detalhes a proposta da coleção Matemática, que ela e outros professores desenvolviam desde a segunda metade da década de 1970 e foi aplicada na escola de 1990 a 1998. Os nossos estudos apontam para a existência de diferentes tipos de resistência, de professores e pais de alunos, na implantação dessa coleção no INSP. Por outro lado, esses estudos também indicam que Martha, atenta a tais dificuldades, incentivava os professores a participarem de cursos e encontros de Educação Matemática, bem como a realizarem novas experiências com seus alunos, que modificavam as propostas da coleção.

A professora Jurema relembra que ela e o Professor Eugênio começaram naquele período a criar diferentes exercícios e atividades, "que foram apresentados na $1^{a}$ Feira de Ciência e Tecnologia do INSP" (GOMES, 2014, p. 209). As atividades envolviam aspectos da História da Matemática, de relações entre Matemática e Arte, privilegiando as transformações geométricas, e de Matemática Lúdica. Essa experiência acabou gerando a proposta de criação de um Laboratório de Matemática, onde algumas aulas dessa disciplina ocorriam. Nas aulas do laboratório, os alunos eram motivados a criar seus próprios mosaicos, utilizando transformações geométricas, bem como a desenvolver várias outras atividades matemáticas, sob a orientação de professores de Matemática e de arte.

Essas e outras maneiras de fazer nos proporcionaram uma compreensão das práticas realizadas no INSP, evidenciando o que é particular a esse ambiente escolar e que pode ser apreendido ao investigar as táticas de apropriação diferenciadas que os professores fizeram com o material que lhes foi apresentado. As modificações surgiram a partir das necessidades que emergiram do cotidiano escolar. Por isso, os professores operaram lance por lance, aproveitando suas próprias experiências com a sala de aula, e com os eventos de Educação 
Matemática dos quais estavam participando, para manipular e alterar o que fora prescrito pelos autores, promovendo mudanças na cultura escolar do Instituto Nossa Senhora da Piedade.

\section{Referências}

CERTEAU, M. de. A Invenção do Cotidiano: artes de fazer. 15 ed. Tradução de E.F. Alves. Rio de Janeiro, RJ: Vozes, 2008.

CHIAPETTI, J. O uso corporativo do território brasileiro e o processo de formação de um espaço derivado: transformações e permanências na região cacaueira da Bahia. 2009. 205f. Tese (Doutorado em Geografia) - Instituto de Geociências e Ciências Exatas, Universidade Estadual Paulista, Rio Claro, 2009.

DANTAS, M. M.S. Ensino da Matemática: um processo entre a exposição e a descoberta. Salvador: Centro Editorial e Didático da UFBA, 1987.

DANTAS, M. M. S. Depoimento. Cadernos do IFUFBA, Salvador, v. 8, n. 1-2, p. 63-84, jul, 1996.

DANTAS, M. M. S., et al. Matemática. Salvador: Editora Fator, s/d.

FIORENTINI, D. Alguns modos de ver e conceber o ensino de matemática no Brasil. Revista Zetetiké, Campinas, v. 3, n. 4, p.1- 37. nov, 1995.

GAERTNER, R.; BARALDI, I. M. Um Ensaio sobre História Oral e Educação Matemática: pontuando princípios e procedimentos. Bolema, Rio Claro, v. 21, n. 30, p. 47-61, jun, 2008.

GARNICA, A.V.M. Um Tema, Dois Ensaios: método, História oral, concepções, Educação Matemática. Bauru. 2005. 205 f. Tese (Livre Docência) - Faculdade de Ciências, Universidade Estadual de São Paulo, Bauru, 2005.

GARNICA, A. V. M. História Oral e História da Educação Matemática: considerações sobre um método. 2011. Disponível em:<www.apm.pt/files/177852_C32_4dd79e66be182.pdf> Acesso em: 22 jun. 2015.

GOMES, L. P. S. Entre a Exposição e a Descoberta: a coleção Matemática e as práticas escolares relacionadas à sua utilização no Instituto Nossa Senhora da Piedade. 2014. 266 f. Tese (Doutorado em Educação) - Faculdade de Educação, Universidade Estadual de Campinas, Campinas, 2014.

IEZZI, G.; DOLCE, O.; MACHADO, A. Matemática e Realidade. São Paulo: Atual Editora Ltda, 1984.

VALENTE, W. R. Osvaldo Sangiorgi, um Best Seller. In: VALENTE, W. R (Org.). Osvaldo Sangiorgi: um professor moderno. São Paulo: Annablume, 2008, p.13-41.

Submetido em Abril de 2015. Aprovado em Agosto de 2015. 